\title{
The Puzzle of Moral Memory
}

\author{
Robert Cowan \\ School of Humanities, University of Glasgow, Glasgow, United Kingdom \\ robert.cowan@glasgow.ac.uk
}

\begin{abstract}
A largely overlooked and puzzling feature of morality is Moral Memory: apparent cases of directly memorising, remembering, and forgetting first-order moral propositions seem odd. To illustrate: consider someone apparently memorising that capital punishment is wrong, or acting as if they are remembering that euthanasia is permissible, or reporting that they have forgotten that torture is wrong. I here clarify Moral Memory and identify desiderata of good explanations. I then proceed to amend the only extant account, Bugeja's (2016) Non-Cognitivist explanation, but show that it isn't superior to a similar Cognitivist-friendly view, and that both explanations face a counterexample. Following this, I consider and reject a series of alternative Cognitivist-friendly explanations, suggesting that a Practicality-Character explanation that appeals to the connection between the practicality of moral attitude and character is superior. However, I conclude that support for this explanation should remain conditional and tentative.
\end{abstract}

\section{Keywords}

memory - moral belief - moral deference - Non-Cognitivism - practicality of moral judgment

My focus is a largely overlooked feature of moral discourse and thought:

Moral Memory $(M M)$ : apparent cases of directly memorizing, remembering, and forgetting first-order moral propositions seem odd.

As paradigm examples, consider:

(A) Martha and I had some free time last night, so we spent the evening memorizing moral truths. 
(B) David asked me if euthanasia is always morally wrong. I immediately felt that I knew the answer. After a little effort, I remembered that euthanasia is sometimes permissible.

(C) Jennifer spent ages racking her brains about the footbridge example. You should have seen how agitated she got! She had completely forgotten that it's impermissible to push the person off the bridge to stop the runaway trolley.

These examples, and others like them, seem odd; roughly, it seems that something isn't right with $(\mathrm{A})-(\mathrm{C})$. This is bound up with a sense of puzzlement: why do $(\mathrm{A})-(\mathrm{C})$ seem odd?

There is a theoretical reason for seeking an explanation of MM. Memory in cognitive discourses - roughly, those involving truth-apt attitudes like beliefsuch as geography, physics, and psychology, is familiar and seems generally unproblematic, e.g. someone memorizes the US states, remembers that electrons have negative charge, or forgets the levels of Maslow's Hierarchy. Given that morality seems cognitive - a claim even Non-Cognitivists typically accept - we would expect moral memory to seem similarly straightforward. Consequently, MM may indicate some distinctive feature(s) of morality (or normativity) which is(are) responsible for the apparent asymmetry with non-moral cognitive domains. Alternatively, the asymmetry could be merely apparent, and the explanation of MM may apply equally in non-moral cases. Either way, explaining $\mathrm{MM}$ is significant for understanding morality.

MM is at least superficially similar to a more familiar phenomenon: moral deference. Despite morality seeming cognitive, and non-moral deference generally seeming straightforward, cases of an agent deferring to another about a moral issue seem odd. ${ }^{1}$ For instance, it seems that something isn't right about my believing that eating meat is immoral purely on the basis of your testimony, and despite my having all of the non-moral information relevant to the issue that you have. Another way in which MM may be related to deference is if

1 Callahan, L.F. (2018) "Moral Testimony: A Re-Conceived Understanding Explanation," Philosophical Quarterly 68:272, 437-459; Hills, A. (2009) "Moral Testimony and Moral Epistemology," Ethics 120(1): 94-127; Howell, R. (2014) "Google Morals, Virtue, and the Asymmetry of Deference," Nous 48 (3):389-415; Fletcher, G. (2016) "Moral Testimony: Once More With Feeling" in Shafer-Landau, R. (ed.), Oxford Studies in Metaethics: volume 11, Oxford University Press, 45-73; Sliwa, P. (2012) “In Defense of Moral Testimony," Philosophical Studies 158 (2):175-195. 
memory involves a successful or failed self-deference. ${ }^{2}$ Thus, there is prima facie reason to think that there may be interesting connections between MM and moral deference.

Unlike moral deference, about which a substantial literature has developed, there are only a few sporadic discussions that are more than loosely related to MM. Relevant are essays by Ryle ${ }^{3}$ and $\mathrm{McGrath}^{4}$ who both discuss the seeming oddity of someone apparently losing a general moral ability - knowing the difference between right and wrong (hereafter "KDBR\&W") - by forgetting. Assuming (as Ryle and McGrath do) that KDBR\&W is not identical to cognizing an individual moral proposition, their target is different from MM. The only paper directly about MM is by Bugeja, ${ }^{5}$ which focuses on forgetting moral propositions, but is clearly intended to be extended to memorizing and remembering. ${ }^{6}$ He defends a Non-Cognitivist explanation, according to which MM stems from our awareness that moral attitudes are non-cognitive, desire states, and the conceptual truth that, necessarily, desires are not memory states. Thus, cases of moral memorizing, remembering, and forgetting are merely apparent, and the seeming oddity is seeming conceptual confusion.

Although Bugeja's Non-Cognitivist explanation is more plausible than the alternatives he considers, I argue ( $\$ 2)$ that it rests on dubious assumptions and should be amended. I then sketch an alternative Non-Cognitivist explanation, but show that it isn't superior to a similar Cognitivist-friendly account that appeals to a "cognitivist" account of desire (or emotion). I end by identifying a counterexample to both kinds of view. Following this, and drawing upon resources from the moral deference literature, I consider and reject a series of alternative Cognitivist-friendly explanations of $\mathrm{MM}\left(\S_{3}-6\right)$, suggesting that a Practicality-Character explanation that appeals to the connection between the practicality of moral attitude and character is superior $(\$ 7)$. I conclude $(\S 8)$ by highlighting wider connections, and recommending that our support for the Practicality-Character explanation should remain conditional and tentative.

2 Cf. Howell (2014: 390).

3 Ryle, G. (1958) "On Forgetting the Difference Between Right and Wrong," in Melden, A. I. (ed.) Essays in Moral Philosophy, Washington, DC: University of Washington Press.

4 McGrath, S. (2015) "Forgetting the Difference Between Right and Wrong" in Grace Chappell, S. (ed.), Intuition, Theory, and Anti-Theory in Ethics, Oxford University Press.

5 Bugeja, A. (2016) "Forgetting Your Scruples," Philosophical Studies 173 (11):2889-2911.

6 Bugeja mentions cases of memorizing and remembering, e.g. pp. 2893-4, 2904, but forgetting takes center stage (see also McGrath and Ryle's articles). 
I here provide initial clarification of MM. I first delineate the kinds of memory and moral proposition within MM's scope. I then explain the focus on seeming oddity and apparent cases.

\section{$1.1 \quad$ Kinds of memory}

MM concerns only propositional memory: ${ }^{7}$ that is, memorizing, remembering, and forgetting propositions, e.g. remembering that Germany's capital is Berlin. ${ }^{8}$ Propositional memory is typically regarded as factive, i.e. $S$ remembers that $\mathrm{p}$ only if $\mathrm{p}$ is true, ${ }^{9}$ although some ${ }^{10}$ impose a stronger knowledge condition, i.e. $\mathrm{S}$ forgot $\mathrm{p}$ only if $\mathrm{S}$ previously knew that $\mathrm{p}$. I'll mostly assume the factivity condition, highlighting the knowledge view where relevant.

Propositional memorizing involves encoding, storing, or retaining information in propositional form. MM concerns cases ${ }^{11}$ of subjects memorizing moral propositions, e.g. someone repeating to themselves that "capital punishment is wrong" or leaving themselves reminders about it. MM also includes firstperson reports like (A) and third-person examples:

(D) Melanie's fridge is covered in post-it notes with moral truths written on them. That's her way of memorizing her duties.

Memorizing examples can be distinguished from cases of moral resolve that don't seem to fall within MM's scope. For instance, if John were tempted to cheat on his husband, it wouldn't be particularly odd for him to repeat or think to himself "I shouldn't break his trust," etc. The natural interpretation is that John is resisting the temptation to violate moral rules that he endorses, rather than encoding or storing a commitment to them.

Propositional remembering involves storing and retrieving information in propositional form. MM concerns cases of subjects remembering moral propositions, e.g. feeling they know the answer to whether euthanasia is permissible,

This is typically distinguished from episodic memory (concerning events in one's past) and procedural memory (concerning skill).

8 Memorizing/remembering/forgetting what, where, who, and why may be elliptical forms of propositional remembering, e.g. "I remember what she said" is roughly equivalent to "I remember that she said such-and-such." See Bernecker, S. (2009), Memory: A Philosophical Study, Oxford University Press, p. 20.

9 Bernecker (2009).

10 E.g. Moon, A. (2013) "Remembering Entails Knowing," Synthese, 190 (14):2717-2729.

11 I drop the "apparent" qualifier for ease of exposition - see §1c for clarification. 
racking their brains, and feeling relief at recalling it. It also includes first-person reports like (B), and third-person examples:

(E) The conversation on capital punishment finally turned to Ian. I wasn't sure what he would say. I breathed a sigh of relief when he remembered that it is always wrong.

Cases (B) and (E) both involve active remembering, i.e. they involve subjects engaging in a more-or-less effortful process which results in information retrieval. There are, however, uses of the term "remember" which don't pick out active remembering, and moral examples seem less odd, e.g. "Ivy knew that capital punishment was wrong years ago when her cousin was on death row, and she still remembers that capital punishment is wrong." Here it's plausible that we interpret the subject not as engaging in active remembering about a moral proposition, but as retaining information about the moral status of something, e.g. capital punishment, and being disposed to attend to the nonmoral features that determine this status.

Propositional forgetting involves the loss of, or temporary inability to access, information stored in propositional form. MM concerns cases of subjects forgetting moral propositions, e.g. someone attempting (but failing) to remember whether promise-keeping is right, feeling frustrated at being unable to do so, and feeling that the answer is on the tip of their tongue. It also encompasses third-person reports like (C) and first-person examples:

(F) I've been thinking to myself: is torture wrong? I've forgotten.

Typically, when someone has forgotten a proposition (moral or otherwise) it's true of them that, were they to try to actively remember the proposition, they would fail (at least initially). Exceptions to this can be found in cases where subjects have ceased to attend to a proposition, but could remember it if prompted, e.g. "I was so focused on getting the promotion that I forgot how important it is to spend time with one's children." Understood as a report that the importance of the person's children hasn't been salient, this attenuated case of moral forgetting doesn't seem odd. If, however, the person couldn't remember (if they tried) that it's morally important to spend time with one's children then the oddity returns. ${ }^{12}$

12 These may be rhetorical uses of "forget" (a similar point may apply to some remembering cases). Rhetorical uses of "forget" don't seem odd, e.g. a politician accuses their opponent of forgetting that the poor have rights. 
Finally, I clarify MM's restriction to direct memorizing, remembering, and forgetting of moral propositions. This excludes cases in which subjects memorize, remember, or forget moral propositions by memorizing, remembering, or forgetting non-moral propositions. The latter indirect cases don't seem odd. To illustrate: it seems okay for someone to memorize the details of WWII naval battles in order to remember the heroism of the service personnel, for someone to recall the moral horror of the Holocaust by remembering what happened (we may have duties to remember such events), ${ }^{13}$ or, for a politician to have forgotten that their speech is sexist due to forgetting their aide's advice about its non-moral content. ${ }^{14}$

Note, however, that the directness restriction includes cases wherein a subject remembers or forgets a moral proposition that was previously believed on the basis of an argument, but has since forgotten the argument. Consider Bugeja's ${ }^{15}$ example:

(G) Don Marquis has an argument which shows that killing people is wrong because it deprives them of their future experiences and projects. Hence killing unborn people is also wrong. This is the argument that made me realize, years ago, that abortion is wrong. Unfortunately I don't have a good memory for philosophical arguments, and I've been embarrassed more than once in debates with defenders of abortion by my inability to remember why we should believe that abortion is wrong. Things recently reached a new low, however. Some acquaintances of mine were arguing about the ethics of abortion. I was called upon to give my opinion on the subject, but I found, to my frustration, that I didn't know what to tell them. This time, not only had I forgotten Marquis's argument, but I'd forgotten that abortion was wrong too.

Despite the subject's moral belief originally held on the basis of a now forgotten argument, $(\mathrm{G})$ is a case of direct moral forgetting and seems odd.

\subsection{Types of moral proposition}

$\mathrm{MM}$ encompasses a wide range of first-order moral propositions. It includes propositions at either end of the spectrum from the obvious to the contentious,

\footnotetext{
13 See Blustein, J. (2008) The Moral Demands of Memory, Cambridge University Press.

14 Indirect cases might not involve moral memory. When considering examples, we may assume that subjects are encoding or retrieving non-moral information, such that it's available for non-memorial moral assessment.

15 (2016: 2896).
} 
e.g. substitution of cases $(\mathrm{A})-(\mathrm{G})$ with the propositions torturing children for fun is wrong (obvious to almost all), or abortion is normally wrong (normally regarded as highly contentious), preserves seeming oddity. MM also includes easily comprehended propositions, e.g. causing pain is bad, and those typically requiring reflection to grasp, e.g. someone forgets whether the Formula of Universal Law is true ${ }^{16}$ or remembers a proposition about a moral dilemma. Finally, everyday moral propositions, e.g. people should keep their promises, and more esoteric ones, e.g. it would be wrong to kill one person to save five, even if the one person is a murderer and promised to sacrifice themselves, are within MM's scope.

Excluded from MM are cases involving non-moral propositions that may nevertheless appear moral. In this category are non-moral sociological propositions, e.g. it doesn't seem odd for an anthropologist to remember that $a$ culture's ritual is morally obligatory. Similar points apply to cases involving children, e.g. "After coming home for his dinner, Johnny asked his father, 'If someone hits you, is it really wrong to hit them back? I can't remember." This seems okay. The absence of seeming oddity may stem from our assumption that children lack fully-fledged moral attitudes, or that they believe non-moral propositions about adults' views. Either way, they don't clearly involve moral memory. Finally, in this category are cases of remembering or forgetting to do something that is morally right, e.g. someone forgets to keep their promise to read a colleague's paper. ${ }^{17}$

\subsection{Seeming oddity and apparent cases}

There are many senses of oddity: confused, incongruous, irrational, etc. MM concerns seeming oddity, i.e. we're more or less immediately struck by oddity. Is there a particular kind or kinds at stake? My view is that the seeming oddity is of incongruity. But given the contentiousness of fine-grained phenomenological claims I don't make it a desiderata of MM explanations that they capture a specific kind of oddity.

A natural thought is that seeming oddity is explained by actual oddity. But some things are odd without immediately seeming so, e.g. a contradiction only

16 Contrast: there is perhaps nothing odd about forgetting the content of the Formula of Universal Law.

17 Cases involving moral why-propositions, e.g. "I know that factory farming is wrong, but can't remember why" generally seem less odd than cases hitherto discussed. This might be because the explanation why something is wrong has an obvious non-moral aspect. Similar points apply to propositions involving thick ethical concepts such as SEXIST or TRUSTWORTHY. 
revealed by complex reasoning. Consider a moral example: if Moral Error Theory were necessarily true then, given the factivity of propositional memory, moral memory would be impossible. But this wouldn't explain seeming oddity, because hardly anyone endorses Error Theory. So seeming oddity may not be explained, even partially, in terms of actual oddity. Indeed, moral memory may not actually be odd at all. ${ }^{18}$ Relatedly, we should be open to the idea that MM is not about memory per se, but instead indicates something else that seems odd.

MM concerns apparent memory cases. There are two reasons for this qualification. First, disingenuous cases of moral memory fall within MM's scope, e.g. someone intentionally lies about having forgotten whether abortion is wrong in order avoid revealing their moral commitments. Even with knowledge of their intentions, it still seems odd to make this excuse. Second, notwithstanding the focus on seeming oddity, it may be that moral memory is impossible, and thus merely apparent.

\subsection{Background Knowledge}

Finally, I note two pieces of background knowledge directly relevant to MM. First, although MM applies to a plethora of hypothetical cases, real-life examples of phenomenological and behavioral symptoms distinctive of memory, or the use of memory language, in moral contexts are unusual., ${ }^{19,20}$ Second, something similar to MM can be found in normative domains like aesthetics and prudence, e.g.

(H) After listening to a performance of Beethoven's Seventh Symphony, Tom asked me what I thought of it. I felt I knew the answer. After some effort, I remembered that it's playful and uplifting.

(I) I've been asking myself: is pleasure worth pursuing for its own sake? I've forgotten.

Although space constraints preclude a full discussion, it's prima facie plausible that $(\mathrm{H})$ and $(\mathrm{I})$ are instances of the same phenomenon as MM.

18 MM is therefore compatible with Plato's view in the Phaedo, that knowledge of the Forms including moral knowledge - is memorial memorable?.

19 In the Nicomachean Ethics (110ob 12 \& 1140b 29) Aristotle notes that virtue is rarely forgotten.

20 However, something like "retrieval" of moral information seems quite common, e.g. you ask me whether capital punishment is wrong and I immediately reply yes. This seems okay. The process either is, or seems similar to, memory. Yet labeling it as remembering seems odd. 
With MM sufficiently clarified, we can note that good explanations of MM should, inter alia, accommodate cases (A)-(G), MM's wide scope, the rarity of real-life cases, and the existence of similar phenomena in other normative domains. I begin by evaluating the only explicitly defended account: Bugeja's Non-Cognitivist explanation.

\section{Non-Cognitivist Explanation}

A Non-Cognitivist explanation of MM requires a plausible characterization of the cognitive/non-cognitive distinction. This is increasingly complex for two reasons. First, contemporary Non-Cognitivists seek to vindicate many of the Cognitivist or Realist-seeming features of moral discourse, e.g. there appears to be moral truth, belief, knowledge, etc. ${ }^{21}$ Second, a popular approach among Non-Cognitivists is to adopt Minimalism about truth, belief, etc. To illustrate, Minimalists about truth think that everything significant there is to say about truth is implied in the following schema: ' $S$ ' is true iff $S$, i.e. to say that a sentence (e.g.) 'Germany's capital is Berlin' is true, is equivalent to asserting that Germany's capital is Berlin. ${ }^{22}$ Since Non-Cognitivists accept that subjects make moral assertions, they can endorse the existence of moral truths, and similar views about moral belief, facts, properties, propositions, representation, etc. But once we adopt Minimalism about a suite of "cognitive" features, it's difficult to distinguish Cognitivism and Non-Cognitivism. ${ }^{23}$

In this context, Bugeja characterizes cognitive attitudes as informationbearing. Moral Non-Cognitivism is the view that necessarily, moral attitudes, e.g. the "belief" that euthanasia is permissible, are not cognitive attitudes. Thus, Non-Cognitivism claims that necessarily, moral attitudes are not informationbearing and there is no such thing as moral information. This characterization is intended to be compatible with Minimalism about truth, belief, etc., but not with Minimalism about information.

What is information? Although Bugeja doesn't provide a characterization, I assume the standard view that information is "any amount of data, code or

21 That there seems to be moral truth and knowledge undermines MM explanations which appeal to their absence. It's also not very plausible that we assume that one's memory is especially unreliable vis-à-vis moral beliefs.

22 Cf. a Robust view that ' $\mathrm{S}$ ' is true because it expresses a proposition which corresponds to the world.

23 See Dreier, J. (2004) "Meta-ethics and the problem of creeping minimalism," Philosophical Perspectives, $18,23-44$. 
text that is stored, sent, received or manipulated in any medium. ${ }^{24}$ What kind of non-cognitive attitudes are moral attitudes? Bugeja favors the view that moral attitudes are desires. ${ }^{25}$ Presumably, these are supposed to be pro/con attitudes towards information, but are not themselves information-bearing. At minimum, this involves the rejection of "cognitivist" accounts of desire according to which desires bear evaluative or normative information about their objects, e.g. that a desire for chocolate informs its subject that the chocolate is $\operatorname{good}$ (in at least some respect). ${ }^{26}$

Here, then, is a charitable reconstruction of Bugeja's explanation of MM:

(1) Desires are non-cognitive.

(2) Moral attitudes are desires.

(3) Necessarily, desires are not memorized, remembered, or forgotten.

(4) Subjects are aware of (1)-(3) when considering examples within MM's scope.

Claims (1) and (2) should be sufficiently clear.

Claim (3) can be understood as a conceptual necessity, i.e. the concepts (and presumably also the real-world entities) of DESIRE, REMEMBERING, etc. are such that it is not metaphysically possible for desires to be, e.g. lost by forgetting. As Bugeja says:

It would be very odd to rack one's brains in order to re-form a lost desire, and to feel relief upon succeeding; and it is not clear that the idea of a conative analogue of memorizing and leaving reminders makes any sense. $^{27}$

Proper understanding of (3) requires grasping the distinction between introversive and extroversive memory, i.e. between memory with respect to propositions about one's own mental states and memory with respect to propositions about the extra-mental world. Consider for example, the belief that Germany's capital is Berlin. This belief can be remembered either introversively (I remember

\footnotetext{
24 Stanford Encyclopedia of Philosophy entry on "Information" https://plato.stanford.edu/ entries/information/.

25 (2016: 2908).

26 Oddie, G. (2005) Value, Reality, and Desire, Oxford; (Gregory, A. (forthcoming) "Might Desires Be Beliefs About Normative Reasons?," in Deonna, J. \& Lauria, F. (eds.) The Nature of Desire, Oxford.

27 Bugeja, p. 2908.
} 
that I believe that Germany's capital is Berlin) or extroversively ${ }^{28}$ (I remember that Germany's capital is Berlin). That is, when recalling my beliefs, "I have a choice between merely reproducing the past content or representing the past mental state as such." ${ }^{29}$ This distinction is important because (3) concerns the non-existence of extroversive memory in the case of desires. It seems straightforward that desires can be remembered introversively, e.g. it seems possible for someone to remember or forget that they want to go to Berlin. However, unlike beliefs, the idea of remembering desires extroversively apparently doesn't make sense, e.g. "John used to like whisky, but you should have seen his look of disgust when he tried the Macallan: he had clearly forgotten." In other words, it seems that desires "can be recalled only by means of introversive memory, for I cannot remember the content of my conative states without remembering their attitudes.", 30,31

Claims (1)-(3) only entail actual oddity. To explain seeming oddity - and hence MM - we need claim (4) that subjects are aware of (1)-(3). "Awareness" does not entail that subjects assent to (1)-(3). Instead, it simply requires certain behavioral, cognitive, and inferential dispositions, e.g. finding cases of extroversive remembering of desires problematic.

Given (1)-(4) we get the prediction that MM cases seem odd, i.e. conceptually confused. However, to be a distinctively Non-Cognitivist explanation the impossibility of extroversive memory with respect to desires (claim (3)) must obtain in virtue of their non-cognitive status (claim (1)). Otherwise, we have a Desire explanation that is compatible with Cognitivism and Non-Cognitivism, i.e. cognitivists about desire could adopt the explanation without claim (1).

Given this, and in light of some of the remarks that Bugeja makes, ${ }^{32}$ he must endorse the following:

(3Info) Necessarily, if $\mathrm{X}$ is an extroversive memory state then $\mathrm{X}$ is information-bearing.

To appreciate 3 Info's plausibility, recall that propositional memorizing and remembering were characterized in terms of encoding, storing, and retrieving

28 The phrase "remembering beliefs," when intended extroversively, might sound strange. It should be understood as an abbreviation for remembering the content of a belief.

29 Bernecker (2009: 23). See Michaelian (2013) for the claim that it's representations that are memorially stored.

$30 \quad$ Ibid, p. 23 .

31 This is compatible with subjects losing desires by extroversively forgetting information about their objects, e.g. I lose my desire to go hiking because I've forgotten what hiking is like. 
of information. Forgetting was understood in terms of informational loss or inaccessibility. Indeed, reference to information is ubiquitous in philosophical characterizations of propositional memory. ${ }^{33}$ In conjunction with (1)-(2) and an appropriately amended (4), this underpins a Non-Cognitivist explanation of MM.

On the positive side, the Non-Cognitivist explanation captures cases (A)(G), MM's wide scope, and the extension into other normative domains (NonCognitivists will likely extend their view to these areas). It might explain rarity, but only with the additional assumption that the relevant conceptual mistake seldom occurs. The explanation also makes a correct novel prediction: that introversive moral memory does not seem particularly odd, e.g. "Is killing morally worse than letting die? That's a tricky one. I wrote a paper about it in graduate school but I really can't remember what my view was." In such cases, it's plausible that we interpret subjects as having forgotten a non-moral aspect of an argument they once held. Odd cases of introversive moral memory may simply be a manifestation of a broader phenomenon: the oddity of memory with respect to one's own psychology.

There are, however, two foundational problems with Bugeja's explanation. ${ }^{34}$ The first concerns his characterization of the cognitive/non-cognitive distinction. Belief, representation, propositions, etc. seem conceptually related to information. Going Minimalist about the former therefore generates a presumption in favor of Minimalism about the latter, e.g. isn't information whatever is conveyed by assertion? But if Minimalism about information is true, this threatens to undermine the Non-Cognitivist explanation since it implies that moral attitudes can bear information (there are, after all, moral assertions), and thus aren't precluded from being extroversive memory states. However, this presumption is only prima facie. It would be canceled if cases of moral information seemed distinctively odd. But consider: "Although I knew she wouldn't listen, I informed Alison that deceiving her husband about their finances is wrong," or "Michelle's gnawing feelings of guilt informed her that she shouldn't have disclosed confidential student information to her partner." These don't seem odd. At any rate, they aren't odder than cases of moral propositions or

33 See, e.g. Bernecker (2009) and Michaelian, K. (2013), "The Information Effect: constructive memory, testimony, and epistemic luck," Synthese (2013) 190:2429-2456.

34 Additionally, the explanation seemingly falsely predicts that moral knowledge ascriptions seem odd, e.g. it's plausible that if $\mathrm{X}$ is a state of knowledge then $\mathrm{X}$ is information-bearing. In reply, Bugeja claims that even if morality is non-cognitive, a cognitive-seeming concept like KNOWLEDGE may seem applicable in the moral domain because of superficial similarities between gaining non-cognitive attitudes and acquiring knowledge, e.g. feelings of confidence, unwillingness to revise, etc. Apparently, there are no such similarities between, e.g. losing non-cognitive attitudes and forgetting. 
representations. Thus, the theoretical basis for Bugeja's Non-Cognitivist explanation is in doubt. ${ }^{35}$

Independent of this, the second problem is that claim (1) - desires are not information-bearing - appears at odds with some standard understandings of information-bearing in psychology and philosophy of mind. For instance, according to Representationalism, propositional attitudes involve mental representations, e.g. "believing that $\mathrm{P}$ involves two psychological elements: a mental representation that $\mathrm{P}$, and the role, characteristic of belief, played by that

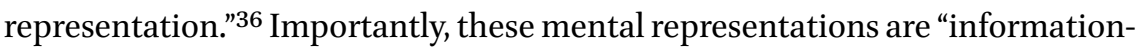
bearing structures. ${ }^{37} \mathrm{So}$, at least in the context of Representationalism, being representational is sufficient for being an information-bearing state. Given that desires (at least propositional desires) are representational, then they are information-bearing, contra claim (1).

Bugeja may of course claim that there are other senses of "informationbearing" or similar terms, such that claim (1), or something closely related, is true. For instance, there may be a sense that beliefs, but not desires, carry information about their objects, even if we concede that they are both information-bearing in the representational sense. However, I suspect that grounding this kind of claim will require appealing to the different functional profiles of beliefs and desires, i.e. information-carrying states are characterized by a distinctive psychological role. This certainly seems suggested by consideration of the Representationalist framework. Functionalists, ${ }^{38}$ who characterize propositional attitudes solely in terms of distinctive dispositional functional profiles, are also likely to make this claim (insofar as they want to draw a distinction between information-bearing/carrying and non-information-bearing/ carrying states). Given this, and Bugeja's lack of clarity on what informationbearing amounts to, it seems preferable to consider a functional explanation directly. ${ }^{39}$

35 Bugeja might reply that, despite appearances, these are really cases of non-moral information (see his 2016, p. 2907, n.15). However, this isn't a plausible reading. For instance, we can assume that, prior to feeling guilty, Michelle already possessed the relevant nonmoral information about what she had done. Her guilt informed her of the distinctively moral quality of her actions.

36 p. 66 in Schroeder, T. (2006) "Propositional Attitudes," Philosophy Compass 1/1, pp. 65-73. For a defense, see, e.g. Fodor, J. (1975) The Language of Thought, Harvard University Press.

37 Stanford Encyclopedia of Philosophy entry on "Mental Representation" https://plato .stanford.edu/entries/mental-representation/.

38 For a defense, see, e.g. Lewis, D. (1972) "Psychophysical and Theoretical Identifications," Australasian Journal of Philosophy, $5^{0}$ (3), 249-258.

39 An alternative: Bugeja might rely upon the "intuitive" sense that desires do not bear information, e.g. doesn't common-sense tell us that losing a belief involves losing information 
Consider, then, a Non-Cognitivist explanation that appeals to the idea that non-cognitive states like desires are distinguished from cognitive states by virtue of their distinctive dispositional-functional role. On one view, a desire that $p$ (roughly) involves being disposed to act and think in various ways to bring about $\mathrm{p}$ in different circumstances, and tends to remain in existence in the presence of not-p. ${ }^{40}$ Perhaps the relevant dispositional-functional features of desires are such that they will fall on the right side of the cognitive/noncognitive divide. ${ }^{41}$ However, in order for this to underpin an explanation of $\mathrm{MM}$, we require further claims about subjects' awareness of those features, and that awareness generates the seeming oddity of moral memory cases. Even if we allow that subjects are relevantly aware - in an attenuated sense - of these features, it's unobvious that this would generate seeming oddity.

Someone might respond by claiming that the following is a conceptual truth we're (in some sense) aware of:

(3Functional) Necessarily, if $\mathrm{X}$ only has the dispositional-functional profile associated with desire, then $\mathrm{X}$ is not an extroversive memory state. ${ }^{42}$

Note that 3 Functional doesn't encompass other allegedly non-cognitive states such as intentions and plans. It thus avoids the worry - raised by Bugeja - that these are extroversive memory states, e.g. "Alice goes to the store to buy milk, but, upon arriving, is unable to remember what she went there for." 43 Given its restrictive scope, however, some might worry that ${ }_{3}$ Functional is an ad hoc postulation. To avoid this charge, the proponent might present platitudes about desires, along with standard Humean arguments against cognitivism

(in some sense), but losing a desire need not? However, even if successful - and the fact that cases of moral information seem okay is a problem - the resulting explanation wouldn't be Non-Cognitivist, since it merely appeals to intuitions about desires and not their nature.

Smith, M. (1994) The Moral Problem, Blackwell.

41 Consider the Explanationist account defended by Dreier (2004) and Simpson, M. (2018) "Solving the Problem of Creeping Minimalism," Canadian Journal of Philosophy, 48 (3-4). According to Simpson's version, Cognitivists and Non-Cognitivists agree that moral language and thought are representational, but are distinguished by the fact that only Cognitivists think that the content of moral language and thought gets explained by its being representational. This might be linked to the allegedly distinctive functional profile of moral attitudes, but work would be required to establish this, e.g. could there be a Minimalist account of (moral) remembering on this view? 
about desire. Crucially, she could also appeal to the fact that desires don't seem to be extroversive memory states, even if intentions and plans are.

However, even if successful, there is a problem with ${ }_{3}$ Functional: just as there are examples suggesting that intentions can be extroversive memory states, there are analogous cases involving desire, e.g. "I got to the shop but couldn't remember what I wanted." So 3 Functional may be falsified.

Further, 3 Functional isn't better supported by the data about desires and memory than an alternative principle:

(3Dual) Necessarily, if $\mathrm{X}$ has the dual dispositional-functional profile associated with desire, then $\mathrm{X}$ is not an extroversive memory state.

That ${ }_{3}$ Dual is a Cognitivist-friendly principle can be recognized by noting that proponents of cognitivist views of desire typically claim that desires have a dual functional profile involving both the profile referred to in ${ }_{3}$ Functional and that associated with belief-like states. ${ }^{44}$ In support, proponents could point to platitudes about desire, present anti-Humean arguments, and of course reference the data about desire and memory. But unlike 3 Functional, additional abductive support for 3 Dual (or something closely related) can be found by considering emotions, the mainstream view about which is that they are cognitive and plausibly have a dual functional profile. ${ }^{45}$ Insofar as it's plausible that desires are not extroversive memory states, it seems that emotions aren't either. ${ }^{46}$ Consider: although emotions can be lost, e.g. I no longer feel heartbroken about my first relationship breaking down, this process is not obviously forgetting. It would also seem odd to rack one's brains to regain a prior emotion, e.g. racking your brains to regain your love for someone (not trying to remember what makes them lovable). And while it's clearly possible to remember or forget that one has/had an emotion, e.g. I remember how joyful I felt at the wedding, these are instances of introversive memory.

My aim is not to defend ${ }_{3}$ Dual, but simply to point out that it seems as well supported by the data as 3 Functional. ${ }^{47}$ This is significant because ${ }_{3}$ Dual

44 See, e.g. Oddie (2005) and Gregory (forthcoming).

45 E.g. Zagzebski, L. (2003) "Emotion and Moral Judgment," Philosophy and Phenomenological Research 66 (1):104-124. Note that this is compatible with a restricted Humean claim that beliefs do not have a dual functional profile.

46 This includes both dispositional and occurrent emotions.

47 It's far from obvious that an explanation deploying ${ }_{3}$ Functional is preferable to one involving 3 Dual according to measures of simplicity, coherence, etc., at least not without begging important theoretical questions against cognitivism about desire/emotion. 
doesn't underwrite a Non-Cognitivist explanation of MM. So, at best, we have reason to think that MM is explained by the identification of moral attitudes with desire or emotion understood along either Cognitivist or Non-Cognitivist lines, i.e. a Desire/Emotion Explanation.

However, in addition to cases suggesting that desires may sometimes be extroversive memory states, there are more troubling examples indicating that Desire/Emotion explanations may be inadequate. This is because they appear falsified by a certain kind of third-person case of moral forgetting wherein the subject does not seem aware that they have forgotten. Consider:

(J) After working on the topic at graduate school, Anna came to know that killing non-combatants in war is always wrong. However, as years passed and she left academia, her knowledge faded. Although she didn't yet realize it, she had forgotten that killing non-combatants is always wrong.

This doesn't seem odd. Yet, prima facie, Desire/Emotion explanations falsely predict the opposite. After all (J) involves apparent extroversive moral forgetting, and analogous third-person cases of extroversively "forgetting" desires do seem odd, e.g. "Rhona used to like chocolate, but over time that desire faded. Although she didn't realize it, she'd forgotten."

In reply, it might be claimed that our awareness of the identification of moral attitudes with desire/emotion is masked when considering case (J). But it's unclear whether this is anything other than an ad hoc move, i.e. given the Desire/Emotion view, what is special about (J)? Although I cannot rule out the possibility of a convincing (unnoticed) response to case (J), I regard the problems I've raised for Desire/Emotion views as constituting sufficient reason for considering alternatives. I therefore turn to assess a series of Cognitivistfriendly explanations.

\section{Perspectival Explanation}

McGrath presents a Cognitivist-friendly explanation of the seeming oddity of the report that 'I used to know the difference between right and wrong, but I don't anymore: at some point, I forgot it' and apparent cases of forgetting this general moral ability.

Before considering whether this could be adapted to explain MM, a brief word about KDBR\&W: according to Ryle and McGrath, it involves the ability to autonomously make correct judgments about a wide range of moral propositions, is partly constituted by propositional moral knowledge, and is 
possessed by a "well brought up child."48 On McGrath's view, the oddity of reporting that you have forgotten this ability is an artifact of perspectival limitations, not due to some deep asymmetry between morality and non-moral domains. Although losing KDBR\&W by forgetting is possible, a person won't typically be in a position to self-ascribe their ignorance: the subject would be self-ascribing a corrupted moral sensibility, yet if they're correct then they typically wouldn't be in a position to recognize this fact. It's a blind-spot proposition for the subject, but need not be for third parties. Thus, the Perspectival explanation predicts that a case like $(\mathrm{J})$ - where the subject does not seem aware that they have forgotten - should seem okay. So it appears to have an advantage over Desire/Emotion explanations.

There are, however, serious problems. First, it's doubtful that the Perspectival account does explain the oddity of first-person forgetting cases. This is because forgetting an individual truth doesn't entail that the agent has a substantially defective sensibility. Nor do we assume this. Indeed, McGrath says that "it would not be plausible to identify forgetting the difference between right and wrong with the forgetting of some particular moral truth, or some small number of moral truths." ${ }^{\text {99 }}$ Second, the Perspectival explanation doesn't have anything to say about memorizing and remembering moral truths, i.e. it's hard to see how perspectival limitations (which are connected to ignorance) could explain such cases. We should reject it.

Some may continue to resist the idea that MM is to be explained in terms of deep and distinctive features of morality, i.e. that there's an asymmetry between moral and non-moral memory. Taking a cue from Sliwa's ${ }^{50}$ work on moral deference, some might argue that reflection on non-moral memory reveals that there's nothing special about MM. Consider:

(K) I've been thinking to myself: is the sky blue? I can't remember.

(L) You should have seen how agitated Finlay got when I asked him whether we have free will. The answer was clearly on the tip of his tongue. Eventually he remembered that we're free.

\begin{tabular}{ll}
\hline 48 & (2015), p. 108. \\
49 & Ibid, p. 119. \\
50 & (2012).
\end{tabular}


(M) I know that Mike was there when Tony got shot. He told me himself. So you can imagine how furious I was when he said this during the TV interview: "Was I there when Tony got killed? Look, I've thought about it a lot these last few weeks but I just can't remember."

The explanations for the seeming oddity of $(\mathrm{K})-(\mathrm{M})$ have nothing much to do with their subject matter. (K) seems odd because of the obviousness of the proposition (how could someone forget that?!), (L) due to contentiousness (how could someone claim to have the truth?!), and (M) because of the bad motives underlying the forgetting claim (attempting to avoid responsibility). In the former case, the seeming oddity is psychological, while in the latter cases, the oddity appears grounded in a norm-violation. Perhaps MM is explainable in terms of this disjunction of features.

However, the Disjunctive explanation is inadequate. First, it's unclear that it explains why case $(\mathrm{J})$ doesn't seem odd. The relevant proposition - killing noncombatants in war is always wrong - is contentious. If forgetting implies truth or knowledge then the Disjunctive explanation (falsely) predicts seeming oddity. Second, and relatedly, the explanation fails to capture MM's wide scope. Specifically, it has nothing to say about cases involving moral propositions that are neither obvious nor contentious. For instance, a memory case involving the Rossian principle that promise-keeping is pro tanto right would seem odd. Yet this proposition isn't regarded as obviously true even among those who think that it is self-evident, and disagreement about it is quite limited, e.g. some Consequentialists and Particularists deny it. At any rate, some disagreement about a proposition doesn't thereby make it contentious, nor does it obviously preclude knowledge. Finally, it's far from obvious that the Disjunctive explanation captures seeming oddity in many cases. When someone claims to have knowledge about a contentious proposition, this might seem inappropriate, but it needn't seem odd. A similar point applies to acting from bad motives.

So even if these features play a contributory role in underpinning MM (e.g. the more obvious the proposition the odder the case, ceteris paribus), they're inadequate as a general account.

\section{Moral Wherewithal Explanation}

Consider another Cognitivist-friendly explanation that denies a deep asymmetry between moral/non-moral memory. Most ethicists will agree that ordinary 
agents possess moral wherewithal: ${ }^{1}$ given full or otherwise adequate non-moral information relevant to a moral proposition, it's normally the case that ordinary subjects can - from the armchair - make a moral assessment that, at least from the first-person perspective, they regard them as having positive epistemic status. ${ }^{52}$ This isn't the claim that moral truths are obvious to everyone. Reflection may be required to ascertain the correct assessment. Neither does it entail the absence of uncertainty. Rather, if agents possess moral wherewithal (hereafter "wherewithal"), then given adequate non-moral information, they won't find themselves dumbfounded or unable to make any seemingly reasonable assessment of moral propositions.

It's plausible that, normally, agents are aware of possessing wherewithal and expect others to be similarly aware. Given these assumptions, the Wherewithal explanation of MM goes as follows. We're in normal circumstances when considering moral memorizing, etc. Thus, we're aware of possessing wherewithal and expect others to be aware. Crucially, however, subjects in relevant cases seem unaware of their wherewithal. Given this apparent violation of our expectation, the cases seem odd (but note that it isn't moral memory per se that seems odd). ${ }^{53}$

To illustrate the claim that subjects seem unaware of their wherewithal, think again about paradigm forgetting cases, e.g. (C) and (F). In these examples it's explicit or implicit that the subject has engaged in failed active remembering. Moreover, forgetting subjects appear dumbfounded about the relevant moral proposition. If they were aware of their wherewithal they would have ceased actively remembering and deployed their wherewithal instead. That they haven't done this and appear dumbfounded strongly indicates wherewithal unawareness.

The Wherewithal explanation explains why cases in which subjects aren't aware that they have forgotten (case (J) above) do not seem odd, since there's no implication that the agent has struggled to remember a moral proposition, and thus doesn't indicate wherewithal unawareness. It may also explain why introversive remembering examples don't seem odd: we may interpret subjects

51 Cf. McGrath, S. (2009) “The Puzzle of Pure Moral Deference," Philosophical Perspectives 23 (1):321-344.

52 Cf. Smith, M. (2004), Ethics and the A Priori, Cambridge, p. 203.

53 Cf. the Intuition view that Bugeja discusses. The Wherewithal explanation requires less controversial assumptions, e.g. it doesn't require a distinction between basic/non-basic moral beliefs and doesn't require positing a mental entity "intuition." 
as recalling non-moral information for moral assessment, or we may interpret such cases of "remembering" as involving the deployment of wherewithal. ${ }^{54}$

The Wherewithal explanation can be extended to other normative domains like aesthetics and prudence insofar as we think we possess relevant wherewithal. It may also explain why cases of memory about philosophical propositions, e.g. see case (L), seem odd. It is, however, a good deal less obvious that it can accommodate the rarity of real-life cases. Just because we possess wherewithal and are normally aware of possessing it doesn't by itself entail that it's rare for us not to use it, e.g. by deploying memory instead. The proponent may therefore need to appeal to psychological facts about our dispositions to deploy wherewithal when considering moral issues as opposed to other kinds of cognizing, e.g. memory. This is of course an empirical matter that I can't resolve here. I note it simply as a lacuna in the account.

In any case, the Wherewithal explanation faces problems. I discuss two. ${ }^{55}$ First, the explanation makes the false prediction that cases in which subjects do seem aware of possessing wherewithal don't seem odd. Consider:

(N) Jim thought again about the murderer at the door example, but couldn't yet work out where the balance of considerations lay. This was annoying because he had made a clear judgment about it in the past. So he tried remembering whether it's permissible to lie to a murderer to protect an innocent person. But that came up short too.

It might be replied that the subject in $(\mathrm{N})$ doesn't seem aware of their wherewithal. To understand this consider another example: "Being unable to work out where I left my keys I racked my brains and managed to remember that they were in the drawer." This seems odd, and does so because the person seems unaware that "working out" where their keys are is just the same process of remembering under a different description. Back in case $(\mathrm{N})$ the thought is that the subject seems similarly unware that "remembering" is really just moral wherewithal.

54 Cf. Evans, G. (1982) The Varieties of Reference, Oxford, on the transparency of mental attitudes.

55 Arithmetical wherewithal may also pose a problem. Although it might seem odd for someone to have apparently forgotten an obviously true proposition like 2+2=4, many arithmetical cases do not, e.g. "Margaret's fridge is covered in the multiplication tables from 11 up to 19. That's her way of memorizing them." One might deny that we take ourselves (and others) to have arithmetical wherewithal. But I doubt that this is true in all relevant cases. 
This response fails. Prior to considering $(\mathrm{N})$, the Wherewithal explanation rested on the assumption that we - who are considering $\mathrm{MM}$ - regard wherewithal and memory as distinct. That's apparently why we want to say to someone engaged in protracted remembering, "just think about the case!" But we're now told that it seems to us that memory and wherewithal substantially overlap. This is ad hoc and threatens to problematize the account of core cases.

Second, the Wherewithal explanation doesn't capture MM's wide scope. Recall that MM includes propositions that may require reflection to comprehend, e.g. moral dilemmas. It's plausible that reflection is also required in order to arrive at a reasonable assessment of their truth. So, when considering memory cases involving these propositions, it's far from obvious that we assume that the subject lacks wherewithal awareness. Rather than thinking through the case again, the subject may simply be employing memory as a short-cut to moral assessment.

In light of the foregoing accounts' difficulties with MM's scope, we may need to appeal to some distinctive feature of morality in order to explain MM. In the following section I consider a token example of a type of explanation, familiar from the moral deference literature, which claims that by failing to deploy one's wherewithal to consider moral propositions, e.g. by using one's memory, one fall shorts short of an ideal that applies in moral or normative domains. ${ }^{56}$

\section{Virtue Explanation}

The starting point for the Virtue explanation ${ }^{57}$ is that there is an ideal of a virtuous agent. They possess virtuous character traits that are suites of reliable affective, cognitive, and motivational dispositions, which in particular instances manifest themselves in appropriate feelings, thoughts, and actions. For instance, being courageous involves reliably feeling fear to the appropriate degree, regarding things as meriting fear when and only when they're dangerous, and standing one's ground in the face of danger when appropriate. A key feature is that the suites of dispositions are integrated, and that distinct character traits are mutually supporting. Crucially, this means that the virtuous

$5^{6}$ There are other similar explanations available, e.g. appealing to authenticity or understanding. Space constraints preclude comparison. However, my objections to the Virtue explanation apply to these alternatives.

57 Inspired by Howell's (2014) account of the oddity of moral deference. 
agent's moral attitudes find rich support within a coherent web of cares and commitments.

The virtuous agent also brings her character to bear on moral issues, i.e. her integrated reliable dispositions constitute her moral wherewithal. Specifically, the virtuous agent's character is engaged with the non-moral morally-relevant features of actions, events, persons, etc. Being affectively and motivationally orientated simply towards the fact that something has a moral feature, e.g. having the property of being wrong, is inappropriate.$^{58}$ As Hills puts it, the virtuous agent is a "moral compass" who is "appropriately orientated"59 towards moral reasons. Characterized as such, virtue may involve a capacity to articulate the moral reasons why certain moral propositions are true (what some call "moral understanding"60), but may often involve "seeing," e.g. emotionally or intuitionally, what to do in particular circumstances. ${ }^{61}$

So construed, virtuous character traits have non-instrumental value. It's therefore plausible that agents are under normative pressure not to act in ways that fall short of, or are in tension with, the ideal of virtue. Further, it's not implausible that, normally, ordinary agents are in some sense aware of these facts, e.g. we expect that moral beliefs will "stem from a person's feelings and intuitions which are indicative of a person's moral character."62

The Virtue explanation's core claim is that, in cases of moral memorizing etc., subjects seem to act in ways that fall short of, or are in tension with, constitutive features of virtue. By engaging their memory, subjects seem to lack the appropriate affective, cognitive, and motivational orientation constitutive of virtue. So moral memory per se seems problematic. Moral memory also indicates a lack of integration of the agent's moral attitudes within their character. Thus, moral memory seems odd in the sense of seeming inappropriate.

To illustrate, consider again remembering cases. Their subjects don't seem to bring their character to bear on the moral issue, thus indicating that they lack virtue. Indeed, since the subjects are engaged in direct moral remembering, i.e. aren't engaged with the non-moral morally-relevant features, they appear inappropriately orientated to morality. Moreover, remembering indicates that the subject's moral attitudes aren't integrated within/are isolated from her character, thus signaling a lack of virtue.

\footnotetext{
$5^{8}$ Cf. Smith (1994).

59 (2009: 112).

$60 \quad$ E.g. Hills, A. (2013) "Moral Testimony," Philosophy Compass 8(6):552-9.

61 Cf. McDowell, J. (1998) "Virtue and Reason" in his Mind, Value, and Reality, Harvard University Press.

62 Howell (2014: 404).
} 
The Virtue explanation captures MM's wide scope: whatever the moral proposition, engaging in moral memory indicates that the subject falls short of virtue. This plausibly includes case $(\mathrm{N})$ which undermined the Wherewithal view. It also captures third-person case $(\mathrm{J})$, because the agent isn't inappropriately orientated towards morality, and there is an explanation as to why their knowledge has been forgotten that is consistent with that attitude previously being integrated. It might be extendable into other normative domains such as aesthetics, although this is unclear. Finally, the account can accommodate introversive cases in much the same way as the Wherewithal explanation, i.e. they involve recovering non-moral information, or implicitly involve deploying character.

Despite its successes, the Virtue explanation may appear to fail in a crucial respect: although it explains/predicts seeming inappropriateness, it fails to capture seeming oddity (cf. the Disjunctive explanation above). Something can seem inappropriate without seeming odd, e.g. if I break my promise without good reason, this seems inappropriate, not odd. It thus may seem that the Virtue explanation misses an important aspect of the phenomenon.

Perhaps the Virtue explanation could account for seeming oddity by appealing to the rarity of real-life cases. However, aside from worries about whether rarity really does generate seeming oddity (cases of humans living above the age of one hundred and ten are rare, but don't seem odd), this leads to the explanation's principal problem: why are real-life memory cases rare? The Virtue explanation appeals to the ideal of virtuous agency. But we often fall short of ideals. ${ }^{63}$ Indeed, it would seem that the Virtue explanation falsely predicts that moral memory cases are as common as promise-breaking.

But this might be too quick. There are some norms that are rarely violated, e.g. against torturing children, or against asking elderly people to give up their seats on crowded subway journeys. So the view isn't automatically undermined by rarity. However, we now require an account of the rarity of the violation of this particular norm (against memorizing, etc.) that appeals to the theoretical framework of the Virtue account. I have doubts about the prospects for this project.

Despite these problems, I think that there is something to the Virtue explanation's claims that not being orientated towards the non-moral reasons is problematic, that there is something amiss about moral attitudes that aren't integrated within one's character, and that moral memory cases exemplify either or both features. However, to explain MM, the problem can't concern virtue. In the penultimate section I sketch an improved account.

63 Cf. Fletcher (2016). 
I suggest that orientation to moral features and lack of integration are (or seem) problematic because of our awareness of a platitude concerning the Practicality ${ }^{64}$ of moral judgment: sincere moral judgments are intimately connected to motivation, and perhaps also feeling. Given this, someone who holds a moral attitude but isn't motivated (or doesn't exhibit relevant feelings) is someone who either doesn't really possess the moral attitude (they may only think that they do) or is psychologically abnormal (they don't care about morality). ${ }^{65}$

The connection between Practicality and orientation is this: someone who isn't orientated towards the non-moral features will typically not be engaging their affective and motivational dispositions, i.e. it's psychologically unusual to be moved simply by the thought that something is wrong independently of engagement with the non-moral features that make it so. Because we are aware of this, in such cases we doubt that the person is going to form/has formed a sincere moral attitude.

The connection between Practicality and integration is this: sincerely held moral beliefs are typically formed by engaging the suites of affective, cognitive, and motivational dispositions that constitute our characters, i.e. our characters at least partly constitute our moral wherewithal. Further, we are aware of these facts. As a result, we expect that an agent's moral attitudes will find support/be integrated within their character. Otherwise why would the attitude be formed?

We can now revisit the connection with MM: in cases of moral memory, subjects don't appear orientated towards the non-moral features, and subjects' moral attitudes don't appear part of an integrated suite of affective, cognitive, and motivational dispositions. The former point simply falls out of the fact that MM is about direct memorizing, etc. Regarding the latter point, consider moral memorizing first. If a subject is engaged in memorizing exercises, it appears that the relevant moral attitude doesn't find support within their character such that it's unclear that the attitude is genuine, or that they're psychologically normal. A similar point holds for moral remembering. Again, the relevant moral attitude doesn't appear to be integrated within the suites of affective,

\footnotetext{
64 Smith (1994).

65 This is compatible with moral motivational internalism and externalism. It's highly plausible that we are in some sense aware of Practicality. Such awareness (or perhaps awareness of some version of internalism or externalism) plausibly provides the best explanation of ordinary agents' intuitive responses to moral motivation cases, e.g. amoralist cases. For a discussion, see Björnsson, G. et al. (eds.) Motivational Internalism, Oxford University Press.
} 
cognitive, and motivational dispositions of the agent. Consequently, we're left wondering about the agent's commitment to the moral attitude/psychological normality. Cases of forgetting are similar to remembering, but perhaps with the additional oddity that the person seems dumbfounded (this explanation assumes that agents possess some degree of moral wherewithal). These features generate a seeming oddity about the relevant cases: a psychological or conceptual incongruity. It seems unusual to engage in mental effort to embed/ retrieve information (which would suggest sincere commitment or care) while at the same time appearing that you aren't committed. Further, this odd scenario will be uncommon.

Given that it appeals to very similar features, the Practicality-Character explanation makes the same predictions about cases as the Virtue explanation, so it would appear to do a good job of capturing MM's scope. But unlike the Virtue account, the Practicality-Character explanation captures seeming oddity and predicts rarity. And we also get a better account of why a similar phenomenon to $\mathrm{MM}$ is found in other normative domains given that analogous assumptions about the nature of character, orientation, integration, and sincerity, etc. seem plausible there too. So, the account seems superior to the views discussed in the foregoing sections.

Despite these successes, some might object that the explanation cannot capture the seeming oddity of subjects immediately remembering a moral proposition. Consider:

(O) When the footbridge example came up again in class, it took Andrew no time at all to remember that it's wrong to push the person off the bridge to stop the trolley. He has a good memory for that sort of thing.

Given Andrew's effortless recall, there is no implication that the moral attitude is unintegrated within his character; hence, there is no suggestion of insincerity or psychological abnormality. Yet $(\mathrm{O})$ seems odd.

Thankfully, the Practicality-Character explanation can capture case $(\mathrm{O})$. First, note that the phrase "he has a good memory for that sort of thing" generates much of the oddity. This implies that Andrew's moral attitudes don't tend to be integrated within his character; that's why having a good memory is of benefit. Second, note that, if we remove the final phrase, the case doesn't seem particularly odd. Any residual oddity can be explained by the PracticalityCharacter explanation in terms of Andrew appearing not to be orientated towards the non-moral features, and hence that he isn't motivationally engaged.

Finally, to philosophers of memory it might seem that the PracticalityCharacter explanation requires taking a stand on unresolved controversies 
in memory theory. Specifically, it requires the assumption that when we engage memory we don't deploy our character, i.e. these are discrete. But this neglects the emergence of plausible constructivist views of memory, according to which memory doesn't simply make stored information available but (at least in episodic memory) involves the deployment of subjects' inferential, non-experiential, and semantic capacities. ${ }^{66}$ The Practicality-Character explanation may require the falsity of analogous views about propositional memory. It would be better to avoid this implication.

To respond we should recall that MM is about seeming, not actual, oddity. Even if memory involves deployment of our character, this isn't how things seem to us, e.g. think of the differences in phenomenology between reflection and effortful remembering. Indeed, the view that memory is a non-constructive process is referred to as the "naïve" 67 view. Thus, the explanation doesn't require a controversial stance on the nature of memory.

\section{Concluding Remarks}

The Practicality-Character explanation of MM captures the desiderata and coheres with general background knowledge, e.g. about the Practicality of moral judgment.

If my arguments are sound, there are two wider connections. First, the Practicality-Character explanation has similarities to extant accounts of moral deference. Clearly, there are commonalities with Howell's view, but the emphasis on motivation is similar to Fletcher's ${ }^{68}$ account, which stresses the connection between moral attitude and motivation/affect. There is clearly potential for a unified account of moral memory and deference along these lines.

Second, my discussion is connected to Ryle and McGrath's topic: the seeming oddity of losing KDBR\&W by forgetting. Ryle's explanation is that KDBR\&W is partly constituted by cares, and cares cannot be forgotten. It should be clear that this is similar to the Desire/Emotion explanations of MM, and thus Ryle's view faces the objections presented in $\S 2$. But note that the PracticalityCharacter explanation's emphasis on motivation/affect is clearly in a similar spirit to Ryle's. McGrath, on the other hand, defends a perspectival explanation of forgetting KDBR\&W $(\S 3)$. The Practicality-Character explanation of MM is

\footnotetext{
66 See, e.g. Michaelian (2013).

67 Michaelian (2013: 2441).

68 (2016).
} 
coherent with McGrath's view, but doesn't entail it. More work thus needs to be done to consider the precise connection.

Although the Practicality-Character explanation has advantages over others discussed, I end by noting reasons for hesitancy about supporting it. First, aspects of the view need further elucidation, e.g. the idea of integration of attitudes within character. Second, some might worry that the explanation's relative complexity makes it difficult to ascertain what predictions it makes about novel cases. Third, some might think that it would be quite a coincidence if desires, emotions, and moral attitudes displayed a similar pattern of oddity with respect to memory without there being something to Desire/Emotion views. Although the Practicality-Character view, which appeals to the connection between moral attitudes and affective/motivational dispositions, arguably goes a way towards capturing this similarity, some might doubt that it does so adequately.

Unfortunately, I lack the space to address these worries, although I am optimistic that they can be assuaged with further work. But in light of these concerns, our support for the Practicality-Character view should remain conditional and tentative. Thus, despite making significant progress, more work is required to solve the puzzle of moral memory.

\section{Acknowledgements}

Many thanks to Jennifer Corns for valuable discussions about the topic. And many thanks to audiences at Hamburg, Glasgow, and Southampton for helpful feedback on previous versions of the paper.

\section{Biographical Note}

Robert Cowan is Lecturer in Philosophy at the University of Glasgow. His research is situated at the intersection of ethics, epistemology, and philosophy of mind. He has published papers on topics in these areas in Canadian Journal of Philosophy, Ethics, and Philosophy and Phenomenological Research. 